\title{
GROWTH RESPONSES OF THE SUBMERGED MACROPHYTE SAGO PONDWEED (POTAMOGETON PECTINATUS) TO DISTURBANCE BY THREE OMNIVOROUS FISHES
}

\author{
WANG, H. L. ${ }^{1,2}-$ LI, Z. F. ${ }^{1,3^{*}}-$ LIU, Y. ${ }^{1}-$ ZhANG, J. W. ${ }^{1}-$ ZhANG, X. K. ${ }^{2}-$ XIE, J. ${ }^{1,3^{*}}$ \\ ${ }^{I}$ Key Laboratory of Tropical and Subtropical Fishery Resource Application and Cultivation, \\ Pearl River Fisheries Research Institute, Chinese Academy of Fishery Sciences, Guangzhou, \\ Guangdong 510380, China \\ ${ }^{2}$ College of Life Science, Anqing Normal University, Anqing, Anhui 246133, China \\ ${ }^{3}$ Guangdong Ecological Remediation of Aquaculture Pollution Research Center, Guangzhou, \\ Guangdong 510380, China \\ ${ }^{*}$ Corresponding authors \\ e-mail:xiejunhy01@126.com,lzf@prfri.ac.cn \\ (Received 19 $9^{\text {th }}$ Dec 2019; accepted $23^{\text {rd }}$ Mar 2020)
}

\begin{abstract}
In China, the distribution area and ecological function of Potamogeton pectinatus have been adversely affected by aquaculture. To evaluate the effects of omnivorous fishes on submerged plant recovery in cultured lakes, growth responses of Potamogeton pectinatus to disturbance by three such fishes (gold fish (Carassius auratus), common carp (Cyprinus carpio), and yellow catfish (Pelteobagrus fulvidraco)) were analyzed. Three stocking densities (low, medium, and high) were selected for each fish species. Fish stocking obviously increased total nitrogen, total phosphorus, conductivity, and total dissolved solids and decreased dissolved oxygen and $\mathrm{pH}$ of the water. Fish species had significant effects on plant height, root length, root dry weight, and aboveground dry weight, which were the lowest after Cyprinus carpio treatment. Stocking density had significant effects only on root length, root dry weight, and aboveground dry weight. The fish species, stocking density, and their interaction had significant effects on total dry weight and biomass allocation. The total dry weight and root:aboveground part values were significantly lower after Cyprinus carpio treatment than after the other treatments. Therefore, the dominant fish species should be scientifically assessed before restoring submerged vegetation, and fish stocking density needs to be controlled to promote submerged macrophyte establishment in cultured lakes.
\end{abstract}

Keywords: cultivated lakes, aquaculture, ecological restoration, stocking density, aquatic plants

\section{Introduction}

Submerged macrophytes are the dominant primary producers in lake ecosystems, and they play important roles in stabilizing embankments, purifying water, and providing shelter for other aquatic organisms (Zhang et al., 2017, 2019; Ge et al., 2018). In China, the distribution area of submerged macrophytes in many freshwater lakes has been greatly reduced due to human activities (Fang et al., 2006; Zhang et al., 2017). The lakes have gradually shifted from a macrophyte-dominated state to a phytoplankton-dominated state (Wu et al., 2019), and the ecological service function is seriously degraded. In addition to factors such as land use change, dam construction, and eutrophication, aquaculture is often considered to be a major reason for the degradation of submerged macrophytes in lakes (Wang et al., 2005; Fang et al., 2006; Wu et al., 2019).

In China, aquaculture is an important part of fisheries. Aquaculture production in the country accounts for $60.5 \%$ of the total production worldwide (Mo et al., 2018). 
However, high fish production in China is mainly achieved through high-density farming. For more economic benefits, many cultured lakes generally stock a high density of fish. Previous studies have shown that high-density stocking of herbivorous or omnivorous fishes can affect submerged plants directly or indirectly (Pipalova, 2006). The direct effects mainly include direct feeding and physical damage by the fishes, for example, grass carp (Ctenopharyngodon idellus) can directly graze on the rhizomes, shoots, and stems of submerged plants, resulting in the decline of aquatic plant resources (Hanlon et al., 2000; Domingues et al., 2017), and the foraging activities of some bottom fishes such as common carp (Cyprinus carpio) and tilapia (Oreochromis mossambicus) which often uproot submerged macrophytes (Chen and Guo, 2005). The indirect effects are mainly attributable to the activities of the fishes. After fish stocking, the suspended matter in the water increases, and more nutrients (such as $\mathrm{N}$ and $\mathrm{P}$ ) are released into the sediment, leading to decreased water transparency and overpopulation of algae and, thus, inhibition of the growth of aquatic plants (Pipalova, 2006; Wang et al., 2016; Hansen et al., 2019).

Recently, the negative impacts of aquaculture have received widespread attention. To restore lake environments, ecological restoration projects have been conducted in many cultured lakes in China (Gu et al., 2018). However, the growth response of aquatic plants affected by different fish disturbances has rarely been reported, and it is difficult to provide a theoretical basis for the restoration of aquatic plants in cultured lakes. Therefore, in this study, we selected three omnivorous fishes, (Carassius auratus, Cyprinus carpio, and Pelteobagrus fulvidraco) that are commonly cultured in lakes in China to determine the growth responses of Potamogeton pectinatus to disturbances by the different fishes at different stocking densities. Although all the three fishes are omnivorous, Pelteobagrus fulvidraco mainly feeds on benthic invertebrates and is less active and causes minimal disturbance in the water body; Carassius auratus mainly feeds on plants and shows relatively strong activity; and Cyprinus carpio mainly feeds on both animals and plants and may cause the strongest disturbance to the water body. Therefore, we hypothesized that the growth responses of Potamogeton pectinatus to disturbances by the different fish species may be different, and its growth was the worst when disturbed by Cyprinus carpio at high stocking density.

\section{Materials and methods}

\section{Experimental design}

Potamogeton pectinatus L. is a perennial submerged macrophyte that can reproduce via vegetative fragments, underground stems, and seeds. On July 22, 2018, similar fragments of Potamogeton pectinatus (35-cm-long apical shoots without developed roots) were collected from Baiyangdian Lake, Hebei Province; transferred to the Baiyangdian field station (N: $115^{\circ} 59^{\prime} 30.31^{\prime \prime}$; E: 38 50'37.12"); and randomly cultivated in rectangular plastic pots $(40 \mathrm{~cm} \times 15 \mathrm{~cm} \times 20 \mathrm{~cm})$. Each plastic pot contained $10 \mathrm{~cm}$ of the substrate (obtained from Baiyangdian Lake). The nutrient content of the substrate (dry weight) was determined to be $1.64 \mathrm{mg} \mathrm{g}^{-1} \mathrm{~N}, 0.52 \mathrm{mg} \mathrm{g}^{-1}$ $\mathrm{P}$, and $24.53 \mathrm{mg} \mathrm{g}^{-1}$ organic matter. Each rectangular plastic pot had 12 seedlings, and three pots were placed in a cement pond $(2.0 \mathrm{~m} \times 2.0 \mathrm{~m} \times 1.8 \mathrm{~m})$ as three replicates. A total of 10 cement ponds were used in this study. Lake water was added to each cement pond. The total nitrogen (TN) and total phosphorus (TP) in the water were 0.980 and 
$0.048 \mathrm{mg} / \mathrm{L}$, respectively; the temperature, dissolved oxygen (DO), conductivity (Cond), total dissolved solids (TDS), and $\mathrm{pH}$ in the water were $28.9^{\circ} \mathrm{C}, 7.70 \mathrm{mg} / \mathrm{L}$, $904 \mathrm{uS} / \mathrm{cm}, 587.9 \mathrm{mg} / \mathrm{L}$, and 8.90, respectively. The water depth was initially maintained at $100 \mathrm{~cm}$ to promote the survival and growth of the seedlings. After half a month, the water depth in the cement pond was increased to $150 \mathrm{~cm}$, and two plants from each pot with large differences in plant size were removed, so that the average plant height of the remaining 10 seedlings was maintained at about $135 \mathrm{~cm}$.

Three omnivorous fishes (Carassius auratus, Cyprinus carpio, and Pelteobagrus fulvidraco) were used, and all of them were captured from Baiyangdian Lake. For each fish species, individuals with a weight of about $100 \mathrm{~g}$ were selected. Three stocking densities were selected for each fish species: high density (HD), medium density (MD), and low density (LD); correspondingly, the number of fishes for the three treatments was 15,10 , and 5, respectively, and the total weight was 1500,1000 , and $500 \mathrm{~g}$, respectively. On August 9, 2019, the three fish species at different stocking densities were placed randomly in each pond. The cement pond with no fish was used as control group. During the experiment, if a fish was found dead, it was replaced with a fish of similar size. No fish were fed throughout the experiment. At the end of the experiment, the temperature, DO, Cond, TDS, and $\mathrm{pH}$ were measured using a portable multiparameter water quality analyzer (YSI Professional Plus, USA). The transparency of the water body was measured using a Secchi disc. The TN and TP of the pond water were determined using standard methods (Lu, 2000).

\section{Data analyses}

The experiment ended on September 22, 2018. All plants were harvested from the plastic pots, and plant height and root length were measured with a meter stick. Then, the plants were divided into root and aboveground (including stems and leaves) parts and dried in an oven at $80^{\circ} \mathrm{C}$ for three days. The dry weight (DW) of the roots, aboveground parts, and whole plants was determined. Two-way analysis of variance (ANOVA) was used to analyze the effects of the fish species and stocking density on plant height, root length, aboveground DW, root DW, and total DW of Potamogeton pectinatus. The normality and homogeneity of all the variables were tested before ANOVA. For variables that satisfied the homogeneity, Tukey's HSD multiple comparisons were used to test for differences between groups, whereas Tamhane's T2 method was used for unequal variances ( $\mathrm{Li}$ et al., 2018). All analyses were performed using Excel and SPSS 13.0 software.

\section{Results}

\section{Physiochemical parameters}

At the end of the experiment, the physiochemical parameters in the different treatment groups showed some differences (Table 1). The TN, TP, Cond, and TDS in all the treatments were obviously higher after fish stocking and transparency was obviously lower than the control. Small differences in the water temperature were observed in all the treatments. The DO and $\mathrm{pH}$ in all treatments with stocked fish (except for Pelteobagrus fulvidraco at LD) were lower than the control values. 
Table 1. Comparison of the physiochemical parameters in the different treatment groups

\begin{tabular}{c|c|c|c|c|c|c|c|c|c|c}
\hline \multirow{2}{*}{ Variable } & \multirow{2}{*}{$\begin{array}{c}\text { Control } \\
\text { group }\end{array}$} & \multicolumn{2}{|c|}{ Pelteobagrus fulvidraco } & \multicolumn{3}{c|}{ Cyprinus carpio } & \multicolumn{3}{c}{ Carassius auratus } \\
\cline { 3 - 10 } & HD & MD & LD & HD & MD & LD & HD & MD & LD \\
\hline Temperature $\left({ }^{\circ} \mathrm{C}\right)$ & 22.9 & 22.9 & 22.6 & 22.5 & 23.3 & 23.2 & 23.0 & 23.2 & 23.0 & 22.9 \\
DO $(\mathrm{mg} / \mathrm{L})$ & 10.16 & 9.08 & 8.98 & 10.45 & 9.40 & 9.61 & 9.28 & 9.69 & 9.15 & 9.84 \\
Cond $(\mathrm{uS} / \mathrm{cm})$ & 586 & 945 & 852 & 869 & 860 & 811 & 665 & 846 & 716 & 664 \\
TDS $(\mathrm{mg} / \mathrm{L})$ & 443.5 & 617.5 & 552.5 & 565.5 & 559.0 & 529.0 & 526.5 & 552.5 & 499.0 & 468.0 \\
pH & 9.48 & 9.15 & 9.16 & 9.69 & 9.08 & 8.82 & 8.90 & 8.81 & 9.02 & 8.95 \\
Transparency $(\mathrm{cm})$ & 150 & 42 & 103 & 105 & 16 & 25 & 32 & 25 & 32 & 62 \\
TN $(\mathrm{mg} / \mathrm{L})$ & 0.215 & 0.393 & 0.341 & 0.232 & 1.243 & 0.646 & 0.477 & 0.656 & 0.341 & 0.246 \\
TP $(\mathrm{mg} / \mathrm{L})$ & 0.039 & 0.045 & 0.048 & 0.058 & 0.198 & 0.100 & 0.079 & 0.082 & 0.069 & 0.069 \\
\hline
\end{tabular}

\section{Morphological parameters}

The fish species had significant effects on plant height, root length, root DW, and aboveground DW of Potamogeton pectinatus, and the values of all four parameters were the lowest after Cyprinus carpio treatment (Table 2; Fig. 1). The root DW and aboveground part DW were lower than the control values after fish stocking; however, the plant height and root length did not show similar trends (Fig. 1).

Table 2. Two-way ANOVA of the effects of fish species, stocking density, and their interactions on plant height, root length, root dry weight $(D W)$, and aboveground $D W$ of Potamogeton pectinatus

\begin{tabular}{c|c|c|c|c|c|c}
\hline $\begin{array}{c}\text { Source of } \\
\text { variation }\end{array}$ & $\begin{array}{c}\text { Plant } \\
\text { height }\end{array}$ & $\begin{array}{c}\text { Root } \\
\text { length }\end{array}$ & $\begin{array}{c}\text { Root } \\
\text { DW }\end{array}$ & $\begin{array}{c}\text { Aboveground } \\
\text { DW }\end{array}$ & $\begin{array}{c}\text { Total } \\
\text { DW }\end{array}$ & Ratio \\
\hline $\begin{array}{c}\text { Fish species } \\
\text { Stocking } \\
\text { density }\end{array}$ & $77.19^{* *}$ & $45.62^{* *}$ & $64.25^{* *}$ & $35.66^{* *}$ & $42.29 * *$ & $3.87 *$ \\
$\begin{array}{c}\text { Fish species } \times \\
\text { Stocking } \\
\text { density }\end{array}$ & 0.78 & $5.65^{* *}$ & $11.76^{* *}$ & $22.86^{* *}$ & $23.32 * *$ & $4.57 *$ \\
\hline
\end{tabular}

Note: $* P<0.05 ; * * P<0.01$

The stocking density had significant effects on root length, root DW, and aboveground DW of Potamogeton pectinatus; however, it had no significant effects on plant height (Table 2). With the increase in stocking density, the root length, root DW, and aboveground DW of the plants showed a significant decrease (Fig. 2). The highest values of all three parameters were observed in the control group, whereas the lowest values were detected in the HD treatment groups (Fig. 2). In addition, the fish species and stocking density had significant interactions with respect to all four morphological parameters (Table 2).

\section{Biomass allocation}

Fish species, stocking density, and their interactions had significant effects on the total DW and root:aboveground part values (Table 1), which were significantly lower in the Cyprinus carpio treatment groups than in the other two fish groups and control group. Although the total DW values after Carassius auratus and Pelteobagrus fulvidraco treatments were lower than the control values, the ratio was not significantly different among the three groups (Fig. 3). With the increase in stocking density, the total DW and ratio showed a tendency to significantly decrease, and both were the lowest after HD treatment (Fig. 4). 

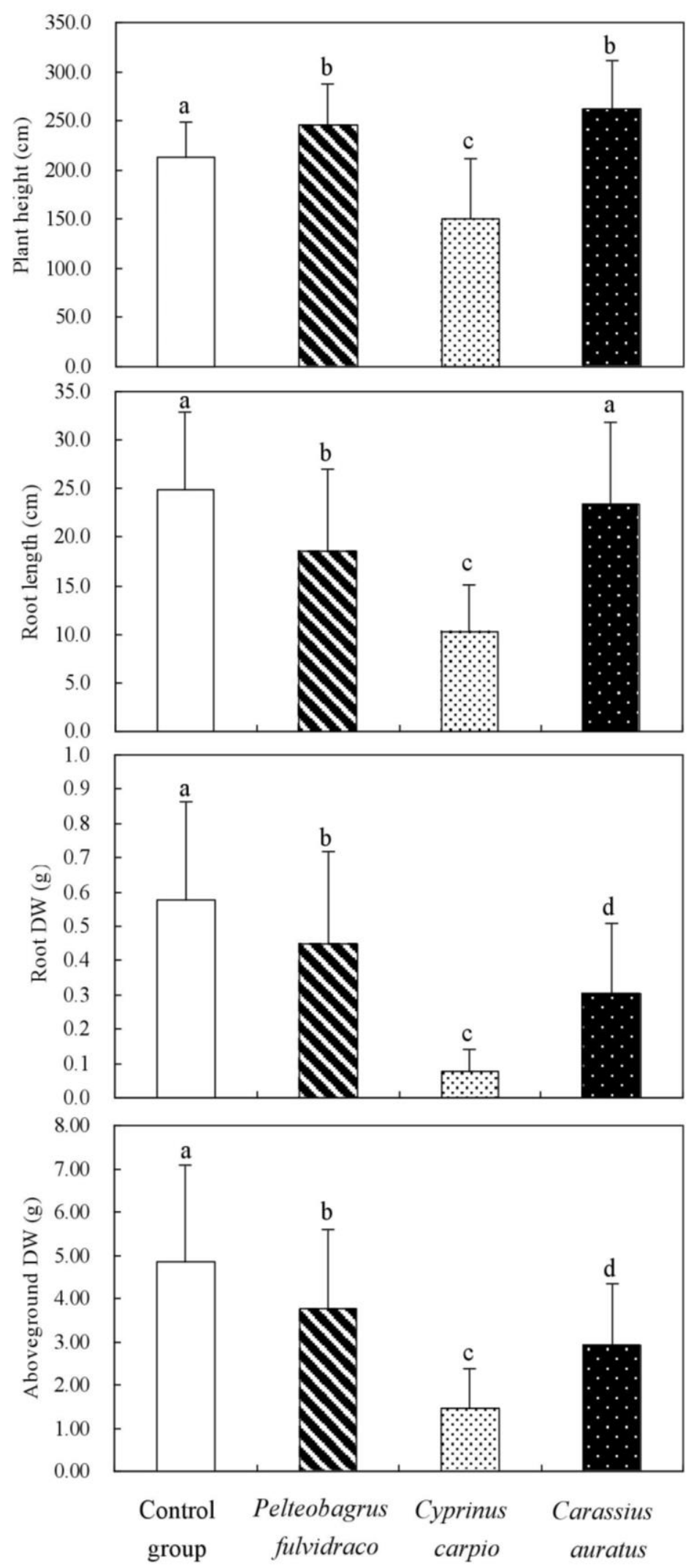

Figure 1. Comparisons of plant height, root length, root dry weight (DW), and aboveground $D W$ after treatment with different fishes. Different lowercase letters indicate significant differences $(P<0.05)$. Error bars indicate the standard deviation of the mean 

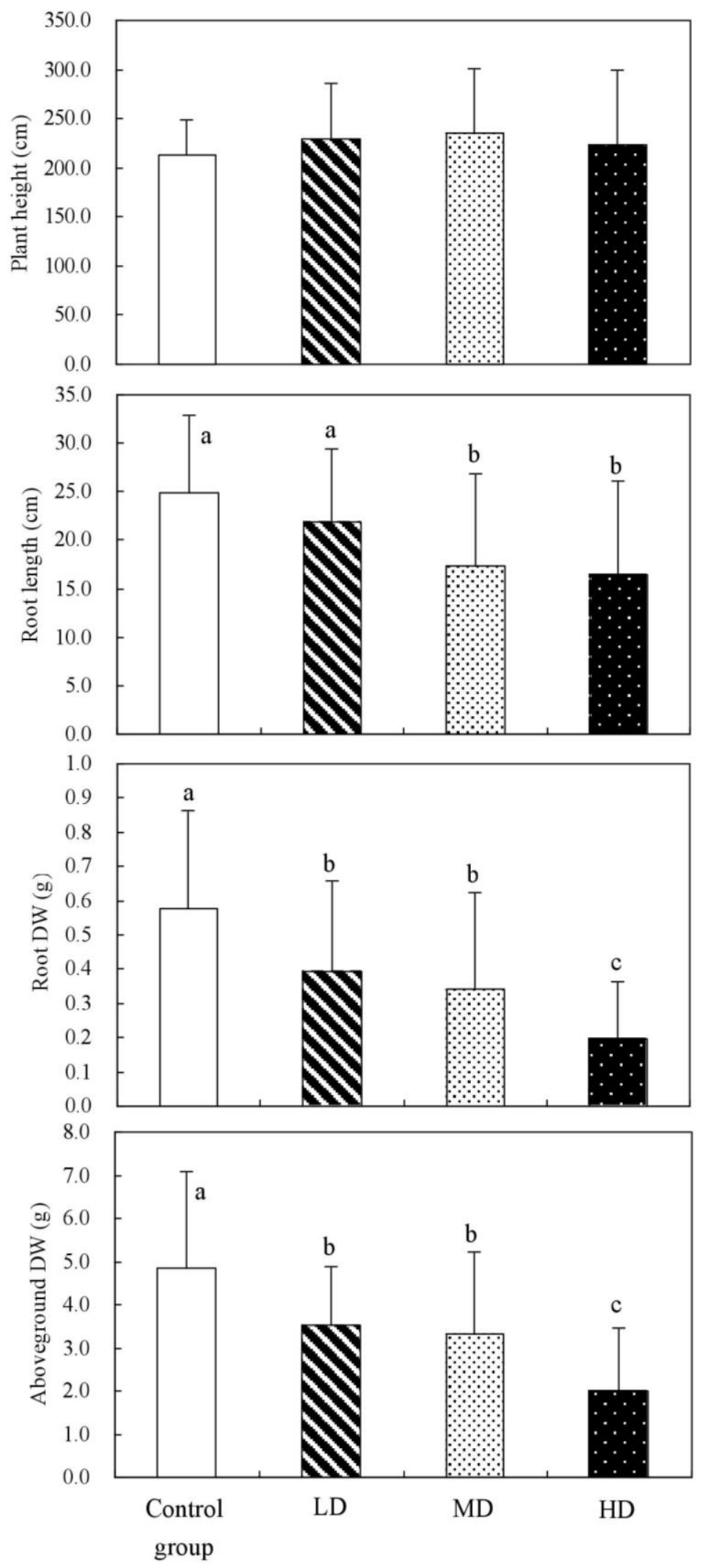

Figure 2. Comparisons of plant height, root length, root dry weight (DW), and aboveground $D W$ under different stocking densities. Different lowercase letters indicate significant differences $(P<0.05)$. Error bars indicate the standard deviation of the mean 

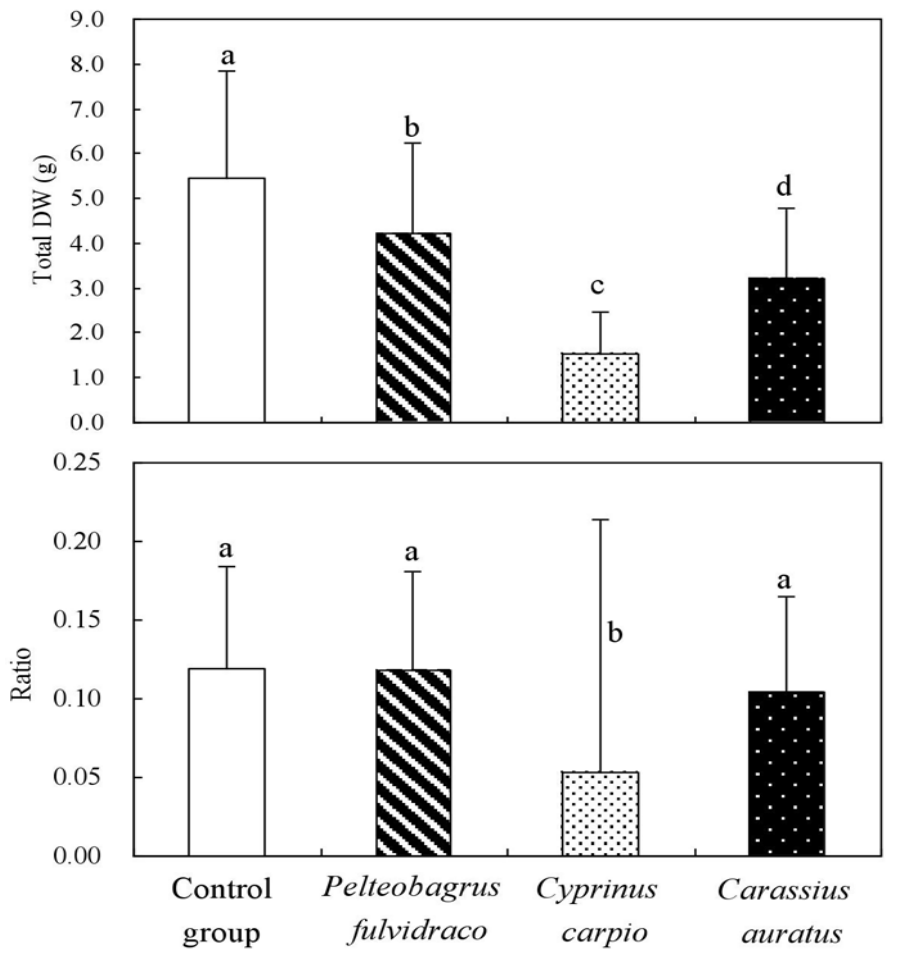

Figure 3. Comparisons of total dry weight $(D W)$ and root:aboveground part values after treatment with the different fishes. Different lowercase letters indicate significant differences $(P<0.05)$. Error bars indicate the standard deviation of the mean

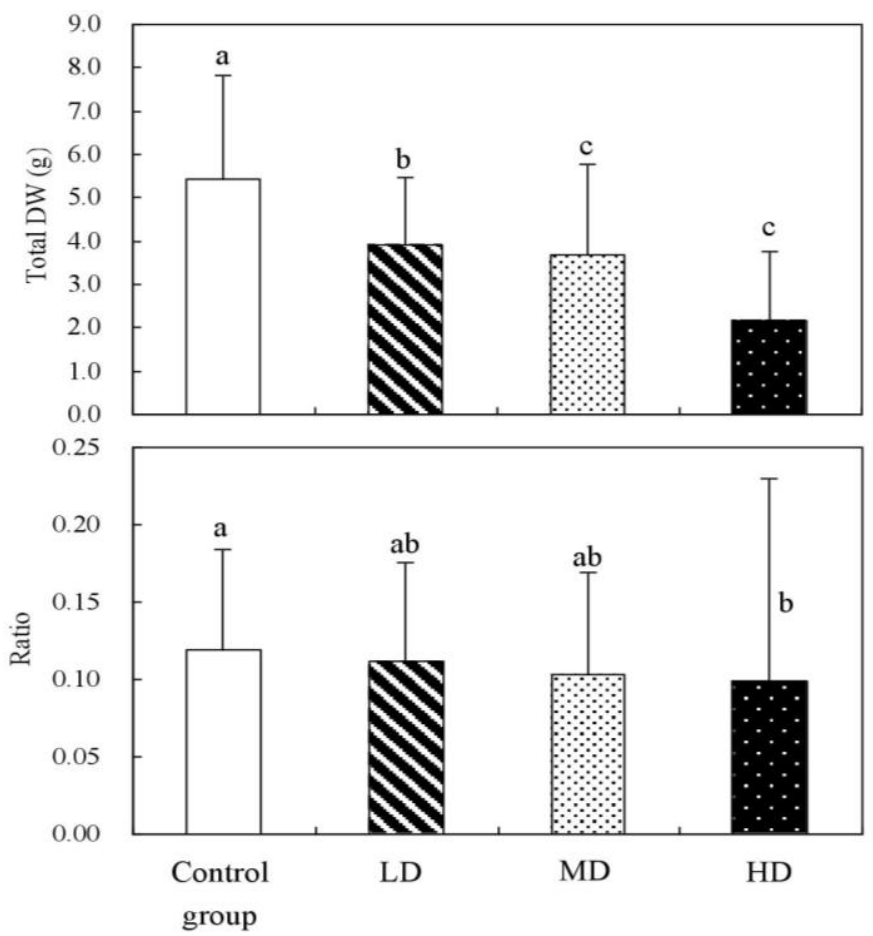

Figure 4. Comparisons of the total dry weight $(D W)$ and root:aboveground part values under different stocking densities. Different lowercase letters indicate significant differences $(P<0.05)$. Error bars indicate the standard deviation of the mean 


\section{Discussion}

In China, fishery plays a very important role in socio-economic development. With the rapid development of freshwater aquaculture fisheries, many freshwater lakes and reservoirs in China are being used intensively (Gu et al., 2018). In 2015, freshwater aquaculture production from the lakes and reservoirs account for $18 \%$ of the total freshwater aquaculture in China (Fisheries Bureau of the Ministry of Agriculture, 2016). Although aquaculture has made great advances in China, its negative impacts on the environment have also received increased attention. The most significant negative impacts are the deterioration of water quality and degradation of aquatic plants because of high-density aquaculture. In this study, the TN, TP, Cond, and TDS were obviously higher in all the treatment groups than in the control group after fish stocking; however, water transparency was obviously lower in all the treatment groups than in the control group. This is consistent with the results of other studies, which indicates that fish stocking increases disturbance to aquatic plants and accelerates the release of nutrients in the sediment (Pipalova, 2006; Wang et al., 2016; Hansen et al., 2019). The Cyprinus carpio treatment groups showed the lowest transparency and highest nutrient content at the same stocking density, whereas the Pelteobagrus fulvidraco treatment groups showed the opposite trend (Table 1). This may because, of the three fish species, Cyprinus carpio disturbs water bodies and aquatic plants to the greatest extent.

Changes in morphology and biomass allocation because of external disturbances are adaptive strategies developed by aquatic plants during long-term evolution (Lytle and Poff, 2004; Merritt et al., 2010; Zhang, 2013). The results of this study show that the fish species and stocking density had significant effects on the morphological parameters and biomass allocation of Potamogeton pectinatus, and the morphological parameters differed in response to fish disturbance. The plant height was significantly higher in the Pelteobagrus fulvidraco and Carassius auratus treatment groups than in the control group, whereas the plant height was significantly lower in the Cyprinus carpio treatment groups than in the control group. This may be mainly because the transparency of the water body gradually decreases with an increase in fish disturbance. To a certain extent, Potamogeton pectinatus can increase its height to avoid the lack of underwater light; however, excessive disturbance significantly inhibits the growth and survival of the plant. Many studies have shown that light availability is the main factor that determines the growth of submerged plants. Aquatic plants tend to produce taller shoots, which is associated with decreased investment in the belowground part in response to decreased light availability (Strand and Weisner, 2001; Zhang et al., 2013; Li et al., 2018). In this study, the root length of the plants after the three different fish treatments was lesser than that of the plants in the control group, which indicates that Potamogeton pectinatus reduced root investment after the stocking of omnivorous fishes. The root:aboveground part value was significantly lower in the Cyprinus carpio groups than in the control group and other two fish groups (Fig. 3); this suggested that the Cyprinus carpio groups caused the largest disturbance, and the plants in the Cyprinus carpio groups invested more resources into aboveground parts than those in the other groups.

The plant height in the different treatment groups did not demonstrate any significant differences as the stocking density increased, but the root length and root:aboveground part values significantly decreased (Fig. 2). The reason for the similar plant heights may be mainly attributable to the shallow water depth in the cement ponds during the experiment (always maintained at $150 \mathrm{~cm}$ ), which limited the space for plant growth. 
The significantly decreased root length and root:aboveground part values indicated the active adaptation of Potamogeton pectinatus to gradually increasing external disturbances. In addition, regardless of the stocking density, the total DW, root DW, and aboveground DW values significantly decreased and were the lowest in the Cyprinus carpio treatment groups. This may be mainly due to the reduced branch number and stem diameter of Potamogeton pectinatus after the fish stocking, which is an active adaptation to weak light conditions caused by the fish stocking. Other studies on the morphological responses of emergent or submerged plants in low light environments have also reported similar findings (Stand and Weisner, 2001; Zhang, 2013; Wang et al., 2018).

Changes in the fish community structure will inevitably affect other aquatic communities and the structure and function of the entire lake ecosystem (Gu et al., 2018; Zhen et al., 2018). A previous study on some temperate lakes has shown that the ultimate cause for the transition from a macrophyte-dominated state to a phytoplanktondominated state is changes in the fish community structure (Brönmark and Weisner, 1992). Therefore, appropriate regulation of fish resources is very important for lake management and submerged plant restoration. To date, studies on the relationships between fish and aquatic plants mainly focused on herbivorous fishes, especially grass carp (Garner et al., 2013; Domingues et al., 2016). Some studies have indicated that irrational stocking of grass carp often leads to the disappearance of many submerged macrophytes in freshwater lakes (Chen and Guo, 2005; Wang et al., 2016; Zhen et al., 2018). However, our study showed that, although the consumption of submerged macrophytes by omnivorous fishes was lower than that by the grass carp, the effects of different omnivorous fishes on the growth of submerged macrophytes have significant differences. For the restoration of submerged plants in cultivated lakes, in addition to reducing the adverse effects of some herbivorous fishes (such as grass carp) on submerged macrophytes, the adverse disturbances caused by omnivorous fishes (such as Cyprinus carpio) need to be considered. On the basis of the results of this study, we suggest strict control of the number of Cyprinus carpio, appropriate control of the number of Carassius auratus, and relaxed control of omnivorous fishes (such as Pelteobagrus fulvidraco) that do not cause much disturbance to submerged macrophytes.

\section{Conclusion}

Both the fish species and stocking density had significant effects on the growth of Potamogeton pectinatus. Generally, the disturbance caused by Cyprinus carpio was the greatest, and the disturbance caused by Pelteobagrus fulvidraco was the lowest. With the increase in stocking density, the disturbance gradually increased. To a certain extent, Potamogeton pectinatus can adapt through changes in the morphological parameters or biomass allocation, but excessive disturbance by fishes significantly inhibits the growth and survival of the plant. Therefore, the dominant fish species should be scientifically assessed before the restoration of submerged vegetation, and appropriate control of fish stocking density is necessary to promote the establishment of submerged macrophytes in cultured lakes. Finally, more field studies are required to determine the joint or single effects of dominant fishes with different feeding habits on the growth of submerged macrophytes and provide a quantitative basis for the restoration of submerged macrophytes. 
Acknowledgements. This study was supported by Test and Demonstration of Agricultural Technology and Service Support (2130106-ZJBYD); Open Foundation of Key Laboratory of Tropical and Subtropical Fishery Resource Application and Cultivation, Ministry of Agriculture; Key Project of Natural Science Foundation for Universities of Anhui Province (KJ2019A0550); and Aquatic Plant Regulation and Landscape Design Program in Baiyangdian Lake (604-180025).

\section{REFERENCES}

[1] Brönmark, C., Weisner, S. E. B. (1992): Indirect effects of fish community structure on submerged vegetation in shallow, eutrophic lakes: an alternative mechanism. Hydrobiologia 243: 293-301.

[2] Chen, X., Guo, Y. (2005): Succession of aquatic vegetation in Lake Xiannv of Lake Xinghu, Zhaoqing City, Guangdong Province. - Journal of Lake Science 17(4): 334-339.

[3] Domingues, F. D., Starling, F. L. R. M., Nova, C. C., Loureiro, B. R., Souza, L. C., Branco, C. W. C. (2016): The control of floating macrophytes by grass carp in net cages: experiments in two tropical hydroelectric reservoirs. - Aquaculture research 48(7): 33563368.

[4] Fang, J., Wang, Z., Zhao, S., Li, Y., Tang, Z., Yu, D., Ni, L., Liu, H., Xie, P., Da, L., Li, Z., Zheng, C. (2006): Biodiversity changes in the lakes of the central Yangtze. - Frontiers in Ecology and the Environment 4(7): 369-377.

[5] Fisheries Bureau of the Ministry of Agriculture of China. (2016): China fishery statistical yearbook. - China Agriculture Press, Beijing.

[6] Garner, A. B., Kwak, T. J., Manuel, K. L., Barwick, D. H. (2013): High-density grass carp stocking effects on a reservoir invasive plant and water quality. - Journal of Aquatic Plant Management 51: 27-33.

[7] Ge, Y., Zhang, K., Yang, X. (2018): Long-term succession of aquatic plants reconstructed from palynological records in a shallow freshwater lake. - Science of the Total Environment 643: 312-323.

[8] Gu, X., Mao, Z., Ding, H., Wang, Y., Zeng, Q., Wang, L. (2018): Progress and prospect of lake fishery in China. - Journal of Lake Science 30: 1-14.

[9] Hanlon, S. G., Hoyer, M. V., Cichra, C. E., Canfield, D. E. (2000): Evaluation of macrophyte control in 38 Florida lakes using triploid grass carp. - Journal of Aquatic Plant Management 38: 48-54.

[10] Hansen, J. H., Brodersen, J., Baktoft, H., Skov, C. (2019): Relationship between bream (Abramis brama) activity and water turbidity in a shallow lake under different season conditions. - Journal of Limnology 78(2): 259-269.

[11] Li, Z., Zhang, X., Wan, A., Wang, H., Xie, J. (2018): Effects of water depth and substrate type on rhizome bud sprouting and growth in Zizania latifolia. - Wetlands Ecology and Management 26: 277-284.

[12] Lu, R. S. (2000): Soil and Agriculture Chemical Analysis Methods. - Chinese Agricultural Science and Technology Press, Beijing.

[13] Lytle, D. A., Poff, N. L. (2004): Adaptation to natural flow regimes. - Trends in Ecology and Evolution 19(2): 94-100.

[14] Merritt, D. M., Scott, M. L., Poff, N. L., Auble, G. T., Lytle, D. A. (2010): Theory, methods and tools for determining environmental flows for riparian vegetation: riparian vegetation-flow response guilds. - Freshwater Biology 55: 206-225.

[15] Mo, W. Y., Man, Y. B., Wong, M. H. (2018): Use of food waste, fish waste and food processing waste for China's aquaculture industry: Needs and challenge. - Science of the Total Environment 613: 635-643.

[16] Pipalova, I. (2006): A review of grass carp use for aquatic weed control and its impact on water bodies. - Journal of Aquatic Plant Management 44: 1-12. 
[17] Strand, J. A., Weisner, S. E. B. (2001): Morphological plastic responses to water level depth and wave exposure in an aquatic plant (Myriophyllum spicatum). - Journal of Ecology 89: 166-175.

[18] Wang, H. Z., Wang, H. J., Liang, X. M., Ni, L. Y., Liu, X. Q., Cui, Y. D. (2005): Empirical modelling of submersed macrophytes in Yangtze lakes. - Ecological Modelling 188(2): 483-491.

[19] Wang, X., Wang, Y., Yang, G., Qin, B., Yang, H. (2016): The effects of different fish species on growth of submerged macrophytes. - Journal of Lake Science 28(6): 13541360.

[20] Wang, H. L., Zhang, X. K., Wan, A. (2018): Morphological responses of Zizania latifolia seedlings at different ages to short-term submergence. - Journal of Lake Science 30(1): 192-198.

[21] Wu, Z. G., Xiong, W., Hou, H. W. (2019): Biodiversity pattern and conservation of aquatic vascular plants in the Yangtze River basin, China. - Acta Hydrobiologica Sinica 43(S1): 27-41.

[22] Zhang, X. (2013): Water level fluctuation requirements of plants in the Yangtze floodplain lakes. - Ph.D. Thesis of University of Chinese Academy of Sciences, Beijing, China.

[23] Zhang, X., Liu, X., Ding, Q. (2013): Morphological responses to water level fluctuations of two submerged macrophytes Myriophyllum spicatum and Hydrilla verticillata. Journal of Plant Ecology 6: 64-70.

[24] Zhang, Y., Jeppesen, E., Liu, X., Qin, B., Shi, K., Zhou, Y., Thomaz, S. M., Deng, J. (2017): Global loss of aquatic vegetation in lakes. - Earth-Science Reviews 173: 259-265.

[25] Zhang, X., Liu, X., Yang, Z., Wang, H. (2019): Restoration of aquatic plants after extreme flooding and drought: a case study from Poyang Lake National Nature Researve. - Applied Ecology and Environmental Research 17(6): 15657-15668.

[26] Zhen, W., Zhang, X., Guan, B., Yin, C., Yu, J., Jeppesen, E., Zhao, X., Liu, Z. (2018): Stocking of herbivorous fish in eutrophic shallow clear-water lakes to reduce standing height of submerged macrophtes while maintaining their biomass. - Ecological Engineering 113: 61-64. 